\title{
Combined exercise circuit session acutely attenuates stress-induced blood pressure reactivity in healthy adults
}

\author{
Sérgio R. Moreira ${ }^{1}$, Ricardo M. Lima ${ }^{2}$, Karina E. S. Silva ${ }^{3}$, \\ Herbert G. Simões ${ }^{4}$
}

\begin{abstract}
Objective: To investigate the blood pressure (BP) responses to cardiovascular stress test after a combined exercise circuit session at moderate intensity. Method: Twenty individuals (10 male $/ 10$ fem; $33.4 \pm 6.9$ years; $70.2 \pm 15.8 \mathrm{~kg}$; $170.4 \pm 11.5 \mathrm{~cm} ; 22.3 \pm 6.8 \%$ body fat) were randomized in a different days to control session with no exercise or exercise session consisting of 3 laps of the following circuit: knee extension, bench press, knee flexion, rowing in the prone position, squats, shoulder press, and $5 \mathrm{~min}$ of aerobic exercise at 75-85\% of age-predicted maximum heart rate and/or 13 on the Borg Rating of Perceived Exertion [scale of 6 to 20]. The sets of resistance exercise consisted of 15 repetitions at $\sim 50 \%$ of the estimated 1 repetition maximum test. Systolic blood pressure (SBP) and diastolic blood pressure (DBP) were measured at rest and during $1 \mathrm{~h}$ of recovery in both experimental sessions. After that, blood pressure reactivity $\left(\mathrm{BP}_{\mathrm{R}}\right)$ was evaluated using the Cold Pressor Test. Results: During $1 \mathrm{~h}$ of exercise recovery, there was a reduction in SBP (3-6 $\mathrm{mmHg})$ and DBP $(2-5 \mathrm{mmHg})$ in relation to pre-session rest $(\mathrm{p}<0.01)$, while this reduction was not observed in the control session. A decline in $\mathrm{BP}_{\mathrm{R}}(4-7 \mathrm{mmHg} ; \mathrm{p}<0.01)$ was observed $1 \mathrm{~h}$ post-exercise session, but not in the control session. Post-exercise reductions in $\mathrm{SBP}$ and $\mathrm{DBP}$ were significantly correlated with $\mathrm{BP}_{\mathrm{R}}$ reductions $(\mathrm{r}=0.50-0.45 ; \mathrm{p}<0.05)$. Conclusion: A combined exercise circuit session at moderate intensity promoted subsequent post-exercise hypotension and acutely attenuated $\mathrm{BP}_{\mathrm{R}}$ in response to a cardiovascular stress test. In addition, the post-exercise $\mathrm{BP}$ reduction was correlated with $\mathrm{BP}_{\mathrm{R}}$ attenuation in healthy adults of both genders.
\end{abstract}

Keywords: blood pressure reduction; vascular reactivity; movement.

Clinical Trials Registration: NCT01935895.

\section{HOW TO CITE THIS ARTICLE}

Moreira SR, Lima RM, Silva KES, Simões HG. Combined exercise circuit session acutely attenuates stress-induced blood pressure reactivity in healthy adults. Braz J Phys Ther. 2014 Jan-Feb; 18(1):38-46. http://dx.doi.org/10.1590/S1413-35552012005000135

\section{Introduction}

The daily stress levels of the general population have been increasing over the last decades ${ }^{1}$. Frequent exposure to stress is considered an important risk factor for the development of cardiovascular diseases $^{2}$. Another well-documented risk factor for cardiovascular disease is systemic hypertension which, in turn, has been related to elevated blood pressure reactivity $\left(\mathrm{BP}_{\mathrm{R}}\right)$ to stress $^{3,4}$. Exacerbated $\mathrm{BP}_{\mathrm{R}}$ may suggest poor autonomic modulation due to increased sympathetic drive, a condition that has been associated with medium to longterm cardiovascular complications ${ }^{5}$. Also, some reports ${ }^{6,7}$ have demonstrated that individuals who are hyperreactive to stress chronically increase their risk for psychological disorders such as anxiety, irritability, and frustration. These feelings are associated with increased sympathetic drive induced by chronic elevation in $\mathrm{BP}^{7,8}$.

Maintaining BP within the normal range can require changes in lifestyle including good nutrition and regular physical activity ${ }^{9,10}$. Several studies have attempted to examine the immediate (acute) benefits of exercise both for healthy individuals ${ }^{11}$ and those with cardiometabolic disorders ${ }^{12,13}$. These studies observed the significant effects of exercise, particularly on hemodynamic control, due to a phenomenon defined as "post-exercise hypotension" 14 . Moreover, 24h ambulatory blood pressure measurements showed a protective effect of previous exercise on $\mathrm{BP}_{\mathrm{R}}$ during activities of daily living, including a greater nocturnal dip in BP, when compared to a control day without exercise $^{15}$.

\footnotetext{
${ }^{1}$ College of Physical Education (CEFIS), Universidade Federal do Vale do São Francisco (UNIVASF), Petrolina, PE, Brazil

${ }^{2}$ Graduate Program in Physical Education, Universidade de Brasília (UnB), Brasília, DF, Brazil

${ }^{3}$ Graduate Program in Physical Education, Universidade Estadual de Londrina (UEL), Londrina, PR, Brazil

${ }^{4}$ Graduate Program in Physical Education and Health, Universidade Católica de Brasília (UCB), Brasília, DF, Brazil

Received: 01/23/2013 Revised: 06/10/2013 Accepted: 08/11/2013
} 
Although the hemodynamic benefits of aerobic and resistance exercises have been documented in a variety of reports ${ }^{5,7,9,10-15}$, the acute effects of the aforementioned exercise modes combined in a circuit method on post-exercise BP, including the responses to a cardiovascular stress test, warrant further investigation. Therefore, the purpose of the present study was to examine the acute BP and stress-induced $\mathrm{BP}_{\mathrm{R}}$ responses following a circuit training session composed of both resistance and aerobic exercises at moderate intensity. Based on the literature ${ }^{11-15}$, we hypothesized that the proposed circuit training session would promote post-exercise hypotension and that this phenomenon would be associated with attenuated stress-induced $\mathrm{BP}_{\mathrm{R}}$.

\section{Method}

To test the hypothesis of the present study, volunteers were invited to participate in two randomly assigned sessions at the exercise physiology laboratory as follows: 1) combined resistance and aerobic exercises performed in a circuit format; and 2) a control session without exercise. In both sessions, $\mathrm{BP}$ was measured at rest and every 15 minutes post-session during 1 hour of recovery following the exercise and non-exercise control sessions. In addition, $\mathrm{BP}_{\mathrm{R}}$ was evaluated using a cardiovascular stress test before and after the experimental sessions. The relationship between post-exercise $\mathrm{BP}$ and $\mathrm{BP}_{\mathrm{R}}$ response to stress test was also examined.

\section{Subjects}

Twenty apparently healthy individuals of both genders (10 men and 10 women), with a mean age of $33.4 \pm 6.9$ years (24-50 years), weight of $70.2 \pm 15.8 \mathrm{~kg}$ (45-96 kg), height of $170.4 \pm 11.5 \mathrm{~cm}(149-192 \mathrm{~cm})$, body mass index $(\mathrm{BMI})$ of $23.9 \pm 3.5 \mathrm{~kg} / \mathrm{m}^{2(-1)}$ $\left(19.2-23.7 \mathrm{~kg} / \mathrm{m}^{2(-1)}\right)$, and body fat percentage of $22.3 \pm 6.8 \%(8.5-35.0 \%)$, volunteered to participate. The classification of the subjects as "apparently healthy" was based on the American College of Sports Medicine (ACSM) guidelines for risk stratification of 1995 (interview to gather information on signs, symptoms and/or cardiopulmonary risk factors). None of the subjects were using any medication or had a history of diagnosed cardiovascular or metabolic disease.

The study was conducted in accordance with the Declaration of Helsinki and was approved by the Ethics Committee of Universidade Federal do Vale do São Francisco, Petrolina, PE, Brazil (protocol 0047.0.441.000-10). All participants were informed of the experimental methods before giving written consent.

\section{Anthropometric assessment}

Standard procedures were used to measure weight, height, and body mass index (BMI). Body density was determined according to specifications by Jackson and Pollock ${ }^{16}$ for men ([1.1093800 - 0.0008267 * (sum of skinfolds of the chest, abdomen and thigh $)+0.0000016 *$ (sum of skinfolds of the chest, abdomen, and thigh $)^{2}-0.0002574 *$ age]) and Jackson et al. ${ }^{17}$ for women ([1.0994921 -0.0009929* (sum of skinfolds of the triceps, suprailiac, and thigh $)+0.0000023 *$ (sum of skinfolds of the triceps, suprailiac, and thigh $)^{2}-0.0001392 *$ age]). Body fat percentage was derived from Siri equation ([4.91 / density -4.5$] * 100$ ).

\section{Blood pressure measurement}

All BP measurements were taken by the same trained technician through the auscultatory method following previously described recommendations ${ }^{18}$, using a stethoscope (Duo Sonic, Brazil) and a calibrated sphygmomanometer (Missouri ${ }^{\circledR}$, São Paulo, SP, Brazil) certified by Inmetro (National Institute of Metrology, Quality, and Technology). Measurements were taken from the left arm with the individual comfortably seated in a quiet room at a controlled temperature of $25{ }^{\circ} \mathrm{C}$. The standard auscultatory method was tested against the automated and previously validated ${ }^{19}$ oscillometric method (Microlife BP 3AC1-1, Microlife USA Inc., Dunedin, FL, USA). Another sample of 30 independent individuals of both genders rested for 10 minutes and their BP was randomly measured using both the auscultatory and oscillometric methods, the latter conducted by another blinded evaluator. Correlations between methods were $\mathrm{r}=0.90(\mathrm{p}<0.001)$ for systolic blood pressure (SBP) and $r=0.80$ $(\mathrm{p}<0.001)$ for diastolic blood pressure (DBP). Also, agreement between methods was evaluated using the Bland-Altman ${ }^{20}$ method. Mean differences were $3.9 \mathrm{mmHg}[20.2 /-12.4 \mathrm{mmHg}]$ and $-3.4 \mathrm{mmHg}$ [10.5/-17.3 mmHg] for SBP and DBP, respectively.

\section{Blood pressure reactivity $\left(\mathrm{BP}_{\mathrm{R}}\right)$ assessment}

$\mathrm{BP}_{\mathrm{R}}$ measurements were performed using the Cold Pressor Test (CPT) according to specifications previously described by Hines and Brow ${ }^{3}$. These authors demonstrated the high reproducibility of the procedure for both normotensive and hypertensive individuals. The protocol consisted of immersing the 
right hand for 1 minute in water carefully maintained at $4{ }^{\circ} \mathrm{C}$ (Incoterm ${ }^{\circledR}$, Porto Alegre, RS, Brazil). BP measurements were respectively taken at 30 and 60 seconds of immersion through the auscultatory method. The two BP values were respectively named Peak30" and Peak60", and the procedure is considered an index of $\mathrm{BP}_{\mathrm{R}}$. $\mathrm{BP}$ was also measured 2 minutes after the end of immersion (After2'). Of note, the adoption of the auscultatory method for BP evaluation was due to the requirement of measurements at 30 and 60 seconds, which would not be possible using the automated oscillometric device.

\section{Experimental sessions}

The volunteers underwent two experimental sessions in random order on different days, 48 to 72 hours apart. The combined exercise session consisted of 3 laps of a circuit with 2 minutes of recovery between laps, including the following resistance and aerobic exercises: knee extension, bench press, knee flexion, rowing in the prone position, squat, shoulder press, and 5 minutes up and down a $15-\mathrm{cm}$ high step at $75-85 \%$ maximum heart rate and/or 13 on the 15-point Borg Rating of Perceived Exertion (RPE), a scale that ranges from 6 to $20^{21}$. Resistance exercise loads were implemented using dumbbells for upper body exercises and weights attached to lower limbs for lower body exercises. Each resistance exercise was performed in sets of 15 repetitions at $50 \%$ of the estimated 1 repetition maximum (1RM) as suggested by Tiggemann et al. ${ }^{22,23}$ with the use of the $\mathrm{RPE}^{21}$. The resistance exercises were performed with rhythmic control (Metronome Plus ${ }^{\circledR}$ ) of one second for the concentric phase and one second for the eccentric phase. The control session was conducted under the same conditions as the combined exercise session, with the exception that the subjects did not perform exercises.

\section{Measurements during the experimental sessions}

Resting SBP, DBP, and mean arterial pressure (MAP) measurements were taken every 5 minutes over a 20-minute period and the average was considered for the analyses (Missouri ${ }^{\circledR}$, São Paulo, SP, Brazil). Also, BP was measured after each circuit lap and every 15 minutes during the 1 hour postexercise recovery. The same timeline and measures were followed during the control session. The CPT was conducted before each session (after 20 minutes of rest) and one hour after the combined exercise and control sessions. Heart rate (HR) was also measured during each exercise and at the respective moment in the control session (Pulse Tronic Club Trainer ${ }^{\circledR}$, Direction Technology Co. Ltd., Taiwan). The HR measurements were considered for aerobic exercise control and identification of the cardiovascular load imposed by the experimental sessions. The RPE was taken during the combined exercise session for control of exercise intensity and the mean value considered for subsequent analyses ${ }^{21}$.

\section{Statistical analysis}

Data are presented using descriptive statistical procedures (mean, standard deviation, minimum and maximum values). The Shapiro-Wilk test was used to verify and present the normality of data distribution. Pearson's correlation was used to examine the relationship between resting BP measured with auscultatory and oscillometric methods, as well as $\mathrm{BP}_{\mathrm{R}}$ in the different moments and the $\mathrm{BP}$ response during and after the exercise and control sessions. The Bland-Altman method ${ }^{20}$ was used to verify agreement between the two BP measurement methods. The paired-samples $t$ test was used to compare data for correspondent moments of experimental sessions. A two-way repeated measures ANOVA was conducted to compare $\mathrm{BP}$ and $\mathrm{BP}_{\mathrm{R}}$ responses within and between experimental sessions [Time (Pre vs. Post) * Session (Exercise vs. Control)]. Data were considered significant at $P<0.05$, and statistical analyses were performed using the SPSS15.0 software (SPSS Inc., Chicago, IL, USA).

\section{Results}

Table 1 presents the mean values for HR and $\mathrm{BP}$ at rest and during both experimental sessions (exercise and control) as well as the mean RPE during the exercise session. The circuit training session elicited a mean cardiovascular intensity of $79 \pm 11 \%$ of maximum HR and a mean RPE of 13 in the 15-point Borg scale.

Figure 1 illustrates BP and HR responses within each experimental session as well as comparisons between sessions. There was a significant decrease in SBP for all evaluated moments after the circuit training session $(\mathrm{p}<0.03)$. No significant changes in SBP were observed after the control session. In addition, SBP response was significantly different in the circuit session when compared to the control session $(\mathrm{p}<0.03)$. For DBP, a significant decrease in relation to rest was observed 60 minutes after the circuit session while a significant increase was noted 45 and 60 minutes after the control session. 
Moreover, DBP response was significantly different in the circuit session when compared to the control session, with higher values for the latter in all of the measurement moments $(\mathrm{p}<0.03)$. For MAP, a significant decrease in relation to rest occurred 30 , 45, and 60 minutes after the circuit session, and these moments were significantly different when compared to the control session $(p<0.03)$. When comparing the HR of the control and circuit sessions, all moments of recovery were different $(\mathrm{p}<0.03)$. However, the HR of the circuit session after 60 minutes of recovery did not differ from the resting HR pre-exercise ( $\mathrm{p}>0.05)$.

Table 2 presents $\mathrm{BP}_{\mathrm{R}}$ before (Pre) and after (Post) the experimental sessions. It was observed that regardless of the measurement moment (i.e. Pre or Post), the CPT elicited significant increases in both SBP and DBP. However, $\mathrm{BP}_{\mathrm{R}}$ was significantly attenuated Post-exercise session when compared

Table 1. Mean $( \pm \mathrm{SD})$ of hemodynamic and perceptual variables at rest and during the exercise and control sessions $(n=20)$.

\begin{tabular}{lccc}
\hline & $\begin{array}{c}\text { Exercise } \\
\text { Session }\end{array}$ & $\begin{array}{c}\text { Control } \\
\text { Session }\end{array}$ & p \\
Resting HR (bpm) & $80 \pm 10$ & $78 \pm 12$ & 0.30 \\
Session HR (bpm) & $147 \pm 21$ & $76 \pm 11$ & 0.01 \\
HR (\%HR maximum) & $79 \pm 11$ & $41 \pm 5$ & 0.01 \\
RPE & $13 \pm 1$ & - & - \\
Resting SBP (mmHg) & $114 \pm 12$ & $113 \pm 12$ & 0.74 \\
Session SBP (mmHg) & $135 \pm 15$ & $112 \pm 11$ & 0.01 \\
Resting DBP (mmHg) & $78 \pm 8$ & $76 \pm 8$ & 0.06 \\
Session DBP (mmHg) & $88 \pm 13$ & $77 \pm 8$ & 0.01 \\
\hline
\end{tabular}

HR: Heart rate; RPE: Rate of perceived exertion; SBP: Systolic blood pressure; DBP: Diastolic blood pressure. $\mathrm{p}=$ comparison between Exercise and Control Sessions.

Table 2. Mean $( \pm \mathrm{SD})$ for blood pressure at rest and blood pressure reactivity responses during (Peak30" and Peak60") and after (After2') the Cold Pressor Test in the pre- (Pre) and post- (Post) experimental session.

\begin{tabular}{lcccc}
\hline & \multicolumn{2}{c}{ SBP (mmHg) } & \multicolumn{2}{c}{ DBP (mmHg) } \\
& Exercise & Control & Exercise & Control \\
Resting & $114 \pm 12$ & $113 \pm 12$ & $78 \pm 8$ & $76 \pm 8$ \\
Peak30" (Pre) & $131 \pm 14 *$ & $129 \pm 14 *$ & $91 \pm 10^{*}$ & $91 \pm 9 *$ \\
Peak60" (Pre) & $132 \pm 13 *$ & $130 \pm 14^{*}$ & $92 \pm 10^{*}$ & $90 \pm 10^{*}$ \\
After2' (Pre) & $115 \pm 12$ & $115 \pm 13$ & $79 \pm 9$ & $79 \pm 10$ \\
Peak30" (Post) & $127 \pm 13 * \dagger$ & $130 \pm 14^{*}$ & $88 \pm 10 * \dagger$ & $93 \pm 15^{*}$ \\
Peak60" (Post) & $126 \pm 12 * \dagger$ & $131 \pm 15^{*}$ & $89 \pm 10 * \dagger$ & $91 \pm 11^{*}$ \\
After2' (Post) & $112 \pm 10 \dagger$ & $117 \pm 13^{*}$ & $78 \pm 9$ & $81 \pm 10^{*}$ \\
\hline
\end{tabular}

SBP: Systolic blood pressure; DBP: Diastolic blood pressure. ${ }^{*} \mathrm{p}<0.05$ compared to resting; $\dagger \mathrm{p}<0.05$ compared the Pre-Session for the same variable. to Pre $(\mathrm{p}<0.05)$. Moreover, SBP was significantly lower at the After2' moment when comparing the Post-exercise session to Pre. For the control session, both SBP and DBP after the CPT (After2') were significantly elevated when compared to resting $(\mathrm{p}<0.05)$. Figure $2 \mathrm{~A}-\mathrm{B}$ depicts $\mathrm{BP}_{\mathrm{R}}$ Pre and Postexercise sessions. Importantly, there was a significant attenuation of $\mathrm{BP}_{\mathrm{R}}$ during and after the CPT postexercise session when compared to the post-no exercise control session $(\mathrm{p}<0.01)$.

In order to show the importance of post-exercise hypotension in relation to the responses of $\mathrm{BP}_{\mathrm{R}}$,
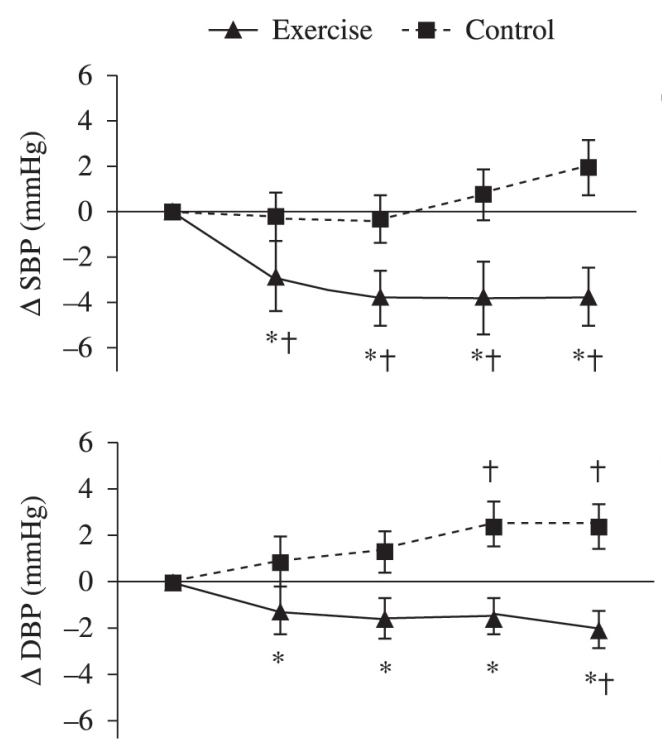

(B)
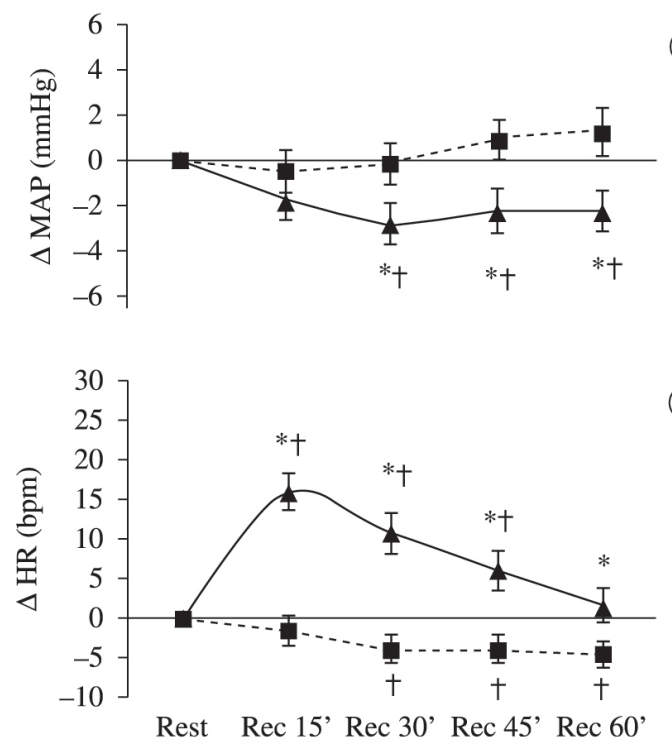

(D)

Figure 1. Range $(\mathrm{mmHg})$ of systolic blood pressure $(\Delta \mathrm{SBP})$, diastolic blood pressure $(\Delta \mathrm{DBP})$, mean arterial pressure ( $\Delta \mathrm{MAP})$, and heart rate $(\Delta \mathrm{HR})$ in the post-exercise session recovery moments (Rec15'-Rec60'). * $\mathrm{p}<0.03$ compared to Control session; $\dagger \mathrm{p}<0.03$ compared to Rest. 

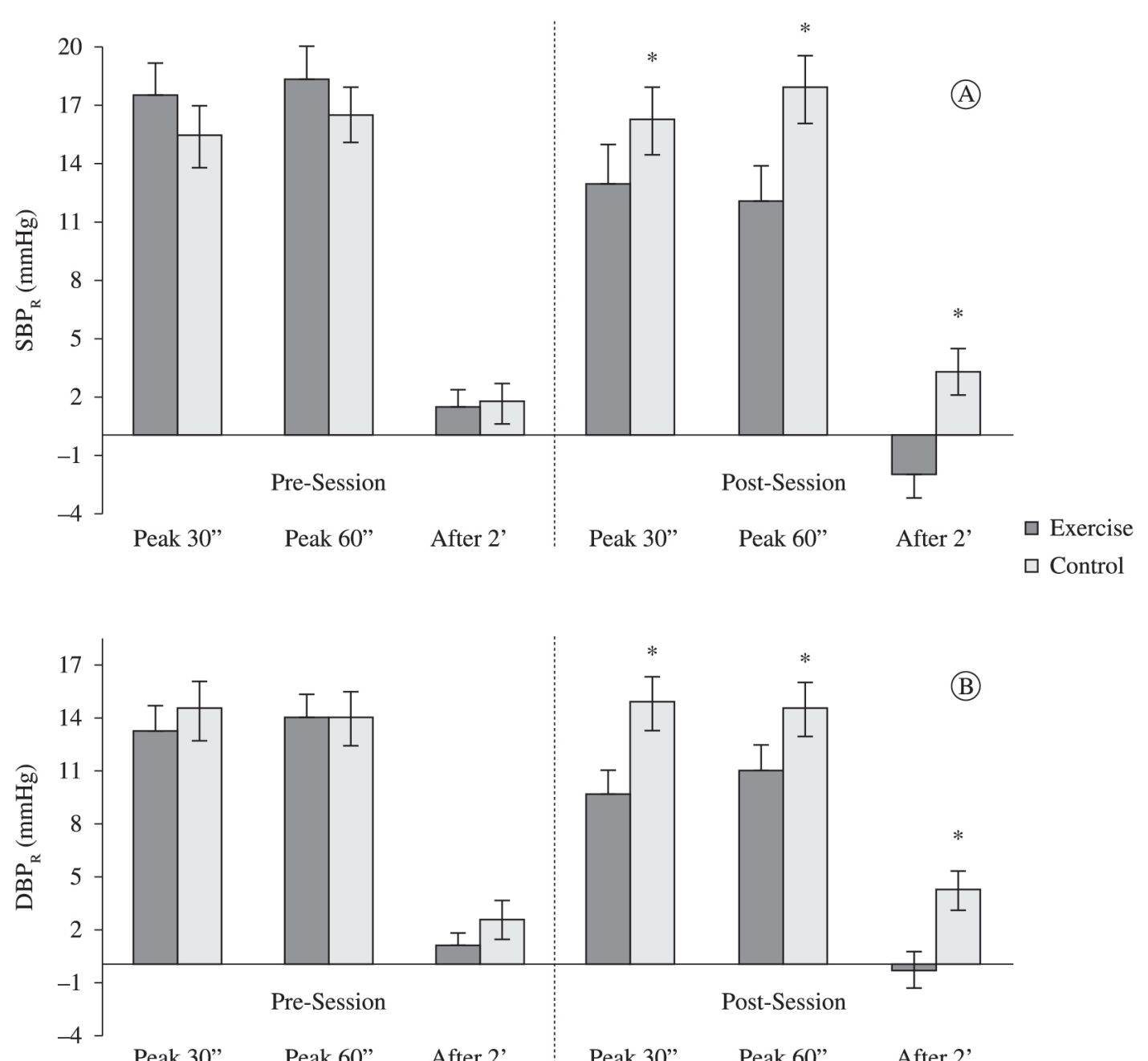

Figure 2. Range ( $\Delta \mathrm{mmHg}$ ) of systolic blood pressure reactivity $\left(\mathrm{SBP}_{\mathrm{R}}\right)$ and diastolic blood pressure reactivity $\left(\mathrm{DBP}_{\mathrm{R}}\right)$ during $\left(\mathrm{Peak}^{2}\right.$ "' and Peak60") and after (After2') the Cold Pressor Test in the pre-exercise session (Pre-Session) and post-exercise session (Post-Session) moments. ${ }^{*} \mathrm{p}<0.01$ compared to exercise session.

Figure 3 presents the correlations between $\mathrm{BP}_{\mathrm{R}}$ and the mean $\mathrm{BP}$ response during one hour of recovery from the experimental sessions. Recovery BP response was positive and significantly correlated with $\mathrm{BP}_{\mathrm{R}}(\mathrm{p}<0.05)$. Despite the moderate intensity of the correlations, they indicate that the greater the decrease in post-exercise $\mathrm{BP}$ is, the greater the attenuation of $\mathrm{BP}_{\mathrm{R}}$ during the CPT (Peak60") will be. In contrast, no significant correlations were found between variables in the control session $(\mathrm{p}>0.05)$.

\section{Discussion}

The main findings of the present study were the occurrence of post-exercise hypotension after a circuit session involving aerobic and resistance exercises and the attenuation of $\mathrm{BP}_{\mathrm{R}}$ in response to subsequent stress induction in apparently healthy adults of both genders. In addition, the observed results suggest that the post-exercise decrease in $\mathrm{BP}$ is associated with the attenuated $\mathrm{BP}_{\mathrm{R}}$ in response to a stressor test. Consistent with previous reports ${ }^{11-15}$, it was observed post-exercise hypotension, however, research on this phenomenon after a combined aerobic and resistance exercise session is still necessary. Moreover, this investigation brings the new finding that the magnitude of post-exercise hypotension is associated with the degree of $\mathrm{BP}_{\mathrm{R}}$ attenuation during stress.

To our knowledge, this is the first study to investigate and compare $\mathrm{BP}$ responses and $\mathrm{BP}_{\mathrm{R}}$ before and after a circuit session of aerobic and resistance exercises in apparently healthy adults of both genders. Significant acute cardiovascular effects of exercise 
Exercise
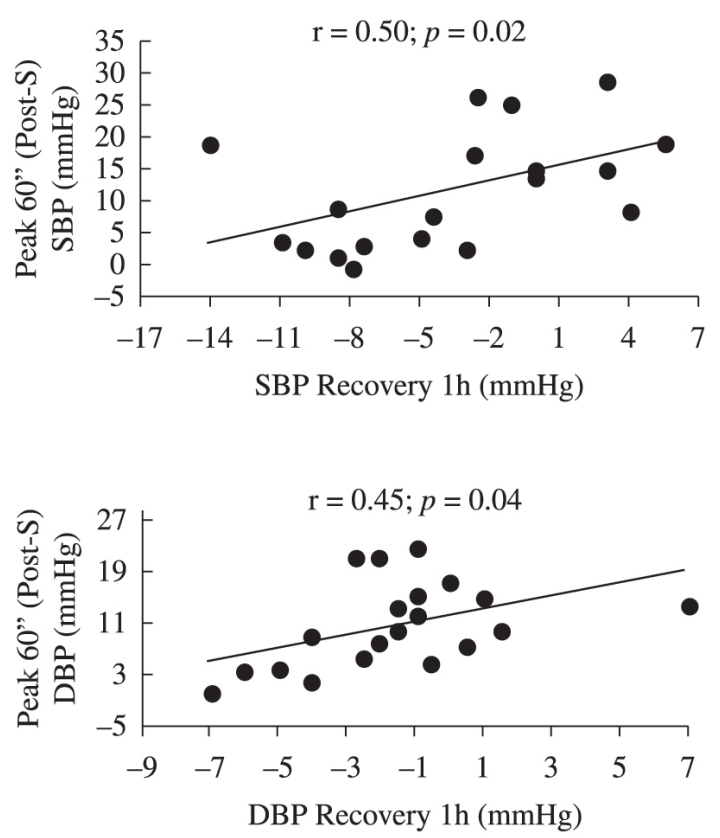

Control
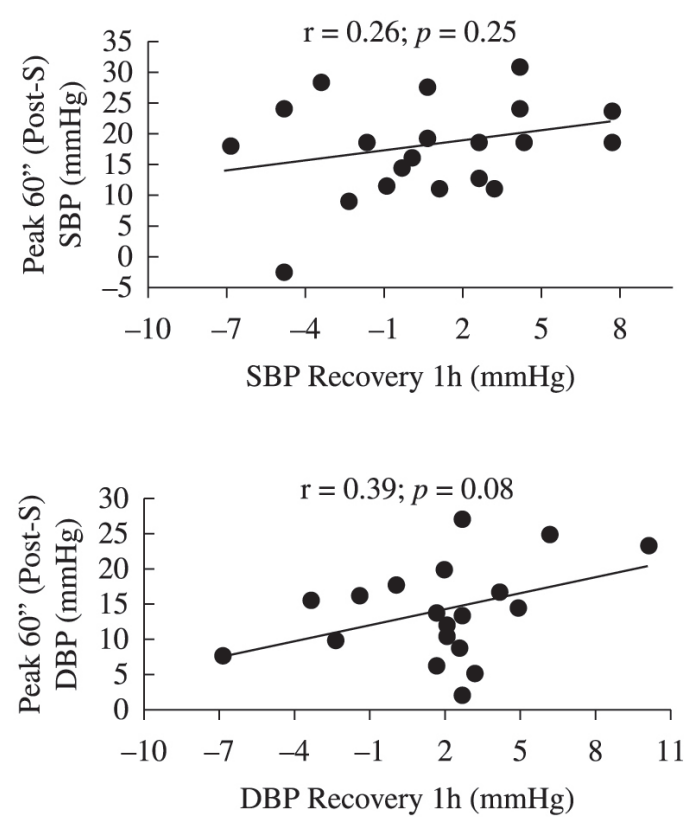

Figure 3. Relationship between the variation in blood pressure reactivity during (Peak60") the Cold Pressor Test post-session (Post-S) and the variation in systolic blood pressure (SBP) and diastolic blood pressure (DBP) after 1 hour of recovery. $\mathrm{p}<0.05$ compared to significant correlation ( $\mathrm{r}$ ).

were observed that suggest a transient cardiovascular protection during rest and induced stress situations even in normotensive individuals. When examining absolute BP values during recovery, we found a favorable reduction only after the exercise session. In contrast, DBP had acutely increased after the control session. This acute exercise-induced reduction in BP was on average 6 and $5 \mathrm{mmHg}$ for SBP and DBP, respectively (Figure 1A-B). Similarly, stress-induced $\mathrm{BP}_{\mathrm{R}}$ was significantly attenuated after the circuit exercise session but not after the control session, reaching a mean difference of $7 \mathrm{mmHg}$ (Figure 2AB). The results presented here can have important clinical implications. Whelton et al. ${ }^{24}$ demonstrated that small changes in BP over a long-term follow-up can have a relevant impact on cardiovascular disease survival. More specifically, the authors showed that reductions of 3 and $5 \mathrm{mmHg}$ can reduce the risk of acute myocardial infarction by 8 to $14 \%$, of coronary artery disease by 5 to $9 \%$, and of overall mortality by 4 to $7 \%$. Furthermore, they showed that a reduction of only $2 \mathrm{mmHg}$ in both SBP and DBP is associated with a decrease of 6 to $14 \%$ and 4 to $6 \%$ in acute myocardial infarction and coronary artery disease, respectively. A small decrease of $2 \mathrm{mmHg}$ in DBP was also associated with a reduction of $17 \%$ in hypertension prevalence in the general population.
Previous reports have demonstrated the protective effect of a single 30-minute exercise session performed at $70 \%$ of maximum oxygen consumption on BP of hypertensive subjects during subsequent activities of daily living ${ }^{25}$. These authors verified an attenuated BP response after exercise in comparison with a control session. Brownley et al. ${ }^{5}$ showed exercise-induced attenuation of $\mathrm{BP}_{\mathrm{R}}$ in young normotensive subjects in response to different modes of stress induction (math and speech challenges). These observations were done while comparing stress responses between pre and post-aerobic exercise conditions. Similarly, in the present study, $\mathrm{BP}_{\mathrm{R}}$ was examined before and 60 minutes after a combined exercise circuit session. A protective effect of exercise was observed during the post-exercise recovery period in relation to the resting pre-exercise period (Figure 1A-C), at the same moments of pre-exercise cardiovascular stress (Table 2), and when comparing the same moments in the control session (Figure 2A-B). A new piece of evidence found here was the significant relationship between post-exercise $\mathrm{BP}$ (i.e. post-exercise hypotension) and $\mathrm{BP}_{\mathrm{R}}$ in response to the CPT (Figure 3). Therefore, it is possible that some mechanisms of exerciseinduced post-exercise hypotension are the same as those underlying attenuated $\mathrm{BP}_{\mathrm{R}}$ after exercise. 
In this sense, the protective effect of exercise on $\mathrm{BP}_{\mathrm{R}}$ in response to stress would be dependent on its capability to elicit post-exercise hypotension, however, further investigation is needed.

Over the last decade, the mechanisms involved in the BP responses to a single bout of exercise have been investigated with a focus on the peripheral and neural pathways ${ }^{14,26}$. Although it was not within the scope of the present study to investigate the mechanisms involved in post-exercise cardiovascular responses, it is plausible that changes in baroreflex sensitivity and the consequent attenuation of sympathetic tone may be involved ${ }^{27}$. Previous studies demonstrated a possible interaction between the release of $P$ substance (a neuropeptide) from the terminals of sensory nerves during exercise and its receptor $\left(\mathrm{NK} 1_{\mathrm{R}}\right)$ in the post-exercise recovery period in conjunction with GABAergic activation. This combination makes the nucleus of the solitary tract more active and consequently inhibits the activity of the ventrolateral medulla, reduces output to sympathetic nerves, finally promoting post-exercise hypotension. Therefore, it is possible that reduced sympathetic tonus is involved in the attenuated $\mathrm{BP}_{\mathrm{R}}$ during the $\mathrm{CPT}$ after a combined exercise circuit session since a significant correlation was noted between post-exercise $\mathrm{BP}$ and $\mathrm{BP}_{\mathrm{R}}$, a condition determined through neural reflex $^{4}$. In contrast, exercise-induced nitric oxide release and thus peripheral resistance reduction may also be involved ${ }^{12,26,28}$. Future studies are necessary to confirm the relationship between those mechanisms and the present results.

Regarding the intensity of the combined exercise circuit protocol, there was a cardiovascular demand of $79 \pm 11 \%$ of age-predicted maximum HR and the mean RPE was $13 \pm 1$ on the 15 -point Borg scale (Table 1). Previous studies examined the acute effects on BP in different populations. Simões et al. ${ }^{13}$ showed the occurrence of post-exercise hypotension in type 2 diabetics after a resistance exercise session performed at $43 \%$ of $1 \mathrm{RM}$, in which the mean RPE was 11-13 on the Borg scale. Motta et al. ${ }^{12}$ investigated the acute effects of aerobic exercise performed at $90 \%$ of the anaerobic threshold in adults of both genders and observed a cardiovascular demand of $80 \%$ of maximum HR and a mean RPE of 13, an intensity similar to the present study. If we also take into account other reports on RPE and blood lactate responses as indexes of resistance exercise ${ }^{29}$ and aerobic exercise ${ }^{30}$ intensity, it is plausible to assume that the combined exercise circuit examined in this study would correspond to a stimulus within the moderate intensity domain. Therefore, exercise protocols within other intensity domains (i.e. intense or severe domains) should be analyzed.

In relation to the design of the experimental exercise session, the practical application is that a combined exercise circuit session involving both aerobic and resistance exercises constitutes an interesting option to attenuate subsequent cardiovascular stress with relatively short sessions (30-40 minutes). The circuit method is also considered more dynamic, which may significantly influence adherence and chronic benefits (i.e. neuromuscular and cardiovascular adaptation).

The main limitations of the present study were no measurements of $\mathrm{BP}_{\mathrm{R}}$ during activities of daily life and no measurements for a longer period but only during the CPT $1 \mathrm{~h}$ post-exercise. It is speculated that this protective effect of combined exercise on $\mathrm{BP}_{\mathrm{R}}$ lasts for a longer period, however more research is needed to investigate this hypothesis. Furthermore, the stress test was shown to be efficient in eliciting cardiovascular stress regardless of the moment it was applied (pre or post-experimental sessions; Table 2). Another limitation was the non-measurement of heart rate variability and nitric oxide release. Those measurements would enable us to examine their relationship with the observed findings and possibly gather information regarding the mechanisms involved.

The results presented here can be useful for professionals involved in prescribing exercise for cardiovascular health. Apparently, healthy adults of both genders aiming to reduce cardiovascular stress, particularly $\mathrm{BP}$ and $\mathrm{BP}_{\mathrm{R}}$, can benefit from circuit training involving aerobic and resistance exercises, with duration ranging from 30 to 40 minutes. The training sessions can consist of a circuit of six resistance exercises, alternating lower and upper body muscle groups, followed by 5 minutes of aerobic exercise. The circuit can be performed in 3 laps with sets of 15 repetitions at $50 \%$ of the estimated 1RM or 13 on the 15-point Borg scale [6-20] for each resistance exercise and a 2-min recovery interval between laps. The aerobic exercise can be conducted using the linear model between $75-85 \%$ of agepredicted maximum HR and/or 13 on the Borg scale.

Despite the potential practical applications of moderate-intensity combined exercise for decreasing $\mathrm{BP}$ and $\mathrm{BP}_{\mathrm{R}}$, previous reports have demonstrated that post-exercise hypotension depends on the intensity ${ }^{13}$. Therefore, higher intensities should be considered for both aerobic and resistance exercises, however prior medical screening including orthopedic, 
cardiovascular, and metabolic evaluation is strongly recommended.

\section{Conclusions}

A single circuit session of resistance and aerobic exercises performed at moderate intensity promoted significant post-exercise decreases in BP. Moreover, $\mathrm{BP}_{\mathrm{R}}$ measures were attenuated during this postexercise hypotension condition. Finally, the decrease in BP was significantly correlated with attenuated $\mathrm{BP}_{\mathrm{R}}$ in healthy adults of both genders.

\section{- Acknowledgments}

We are grateful to Conselho Nacional de Desenvolvimento Científico e Tecnológico (CNPq), Brazil (proc. 474328/2010-4) for their financial support. We also wish to extend our acknowledgments to Salvapé Produtos Ortopédicos Ltda. for donating the digital BP equipment.

\section{References}

1. Taylor M, Barr M, Stevens G, Bryson-Taylor D, Agho $\mathrm{K}$, Jacobs J, et al. Psychosocial stress and strategies for managing adversity: measuring population resilience in New South Wales, Australia. Popul Health Metr. 2010;14:28. PMid:20942975 PMCid:PMC2965129. http://dx.doi.org/10.1186/1478-7954-8-28

2. Figueredo VM. The time has come for physicians to take notice: the impact of psychosocial stressors on the heart. Am J Med. 2009;122:704-12. PMid:19635269. http:// dx.doi.org/10.1016/j.amjmed.2009.05.001

3. Hines EA, Brow GE. The cold test pressor for measuring the reactibility of the blood pressure: data concerning 571 normal and hypertensive subjects. Am Heart J. 1936;11:19. http://dx.doi.org/10.1016/S0002-8703(36)90370-8

4. Wood DL, Sheps SG, Elveback LR, Schirger A. Cold pressor test as a predictor of hypertension. Hypertension. 1984;6:301-6. PMid:6735451. http://dx.doi. org/10.1161/01.HYP.6.3.301

5. Brownley KA, Hinderliter AL, West SG, Girdler SS, Sherwood A, Light KC. Sympathoadrenergic mechanisms in reduced hemodynamic stress responses after exercise. Med Sci Sports Exerc. 2003;35:978-86. PMid:12783046. http://dx.doi.org/10.1249/01.MSS.0000069335.12756.1B

6. Lipp ME, Pereira MM, Justo AP, Matos TM. Cardiovascular reactivity in hypertensives: differential effect of expressing and inhibiting emotions during moments of interpersonal stress. Span J Psychol. 2006;9:154-61. PMid:17120695.

7. Lavie CJ, Milani RV. Depression, autonomic function, and cardiorespiratory fitness: comment on Hughes, et al. (2010). Percept Mot Skills. 2011;112:319-21. PMid:21466105. http://dx.doi.org/10.2466/02.06.15.20. PMS.112.1.319-321
8. Das S, O'Keefe JH. Behavioral cardiology: recognizing and addressing the profound impact of psychosocial stress on cardiovascular health. Curr Hypertens Rep. 2008;10:374-81. PMid:18775114. http://dx.doi. org/10.1007/s11906-008-0070-6

9. Locks RR, Costa TC, Koppe S, Yamaguti AM, Garcia MC, Gomes ARS. Effects of strength and flexibility training on functional performance of healthy older people. Rev Bras Fisioter. 2012;16(3):184-90. PMid:22801513. http:// dx.doi.org/10.1590/S1413-35552012000300003

10. Gaesser GA, Angadi SS, Sawyer BJ. Exercise and diet, independent of weight loss, improve cardiometabolic risk profile in overweight and obese individuals. Phys Sportsmed. 2011;39:87-97. PMid:21673488. http://dx.doi. org/10.3810/psm.2011.05.1898

11. Lizardo JHF, Simões HG. Efeitos de diferentes sessões de exercícios resistidos sobre a hipotensão pós-exercício. Rev Bras Fisioter. 2005;9(3):249-55.

12. Motta DF, Lima LC, Arsa G, Russo PS, Sales MM, Moreira SR, et al. Effect of type 2 diabetes on plasma kallikrein activity after physical exercise and its relationship to post-exercise hypotension. Diabetes Metab. 2010;36:363-8. PMid:20579916. http://dx.doi. org/10.1016/j.diabet.2010.03.008

13. Simões GC, Moreira SR, Kushnick MR, Simões HG, Campbell CS. Postresistance exercise blood pressure reduction is influenced by exercise intensity in type- 2 diabetic and nondiabetic individuals. J Strength Cond Res. 2010;24:1277-84. PMid:20386125. http://dx.doi. org/10.1519/JSC.0b013e3181d67488

14. Tipton CM. Concerning postexercise hypotension. Exerc Sport Sci Rev. 2011;39:109. PMid:21430451. http:// dx.doi.org/10.1097/JES.0b013e3182164376

15. Morais PK, Campbell CS, Sales MM, Motta DF, Moreira $\mathrm{SR}$, Cunha VN, et al. Acute resistance exercise is more effective than aerobic exercise for $24 \mathrm{~h}$ blood pressure control in type 2 diabetics. Diabetes Metab. 2011;37:1127. PMid:21159536. http://dx.doi.org/10.1016/j. diabet.2010.08.008

16. Jackson AS, Pollock ML. Generalized equations for predicting body density of men. 1978. Br J Nutr. 2004;91(1):161-8. PMid:14748950.

17. Jackson AS, Pollock ML, Ward A. Generalized equations for predicting body density of women. Med Sci Sports Exerc. 1980;12:175-81. PMid:7402053. http:// dx.doi.org/10.1249/00005768-198023000-00009

18. Perloff D, Grim C, Flack J, Frohlich ED, Hill M, McDonald M, et al. Human blood pressure determination by sphygmomanometry. Circulation. 1993;88:246070. PMid:8222141. http://dx.doi.org/10.1161/01. CIR.88.5.2460

19. Stergiou GS, Tzamouranis D, Protogerou A, Nasothimiou E, Kapralos C. Validation of the Microlife Watch BP Office professional device for office blood pressure measurement according to the International protocol. Blood Press Monit. 2008;13:299-303. PMid:18799957. http://dx.doi. org/10.1097/MBP.0b013e3283057af6

20. Bland JM, Altman DG. Statistical methods for assessing agreement between two methods of clinical measurement. 
Lancet. 1986;8:307-10. http://dx.doi.org/10.1016/ S0140-6736(86)90837-8

21. Borg G. Ratings of perceived exertion and heart rates during short-term cycle exercise and their use in a new cycling strength test. Int J Sports Med. 1982;3:153-8. PMid:7129724. http://dx.doi.org/10.1055/s-2008-1026080

22. Tiggemann CL, Korzenowski AL, Brentano MA, Tartaruga MP, Alberton CL, Kruel LF. Perceived exertion in different strength exercise loads in sedentary, active, and trained adults. J Strength Cond Res. 2010;24(8):203241. PMid:20634752. http://dx.doi.org/10.1519/ JSC.0b013e3181d32e 29

23. Tiggemann CL, Pinto RS, Kruel LF. Perceived Exertion in Strength Training. Rev Bras Med Esporte. 2010;16(4):3019. http://dx.doi.org/10.1590/S1517-86922010000400014

24. Whelton PK, He J, Appel LJ, Cutler JA, Havas S, Kotchen TA, et al. Primary prevention of hypertension: clinical and public health advisory from the National High Blood Pressure Education Program. JAMA. 2002;288:1882-8. PMid:12377087. http://dx.doi. org/10.1001/jama.288.15.1882

25. MacDonald JR, Hogben CD, Tarnopolsky MA, MacDougall JD. Post exercise hypotension is sustained during subsequent bouts of mild exercise and simulated activities of daily living. J Hum Hypertens. 2001;15:567-71. PMid:11494096. http://dx.doi.org/10.1038/sj.jhh.1001223

26. Halliwill JR. Mechanisms and clinical implications of post-exercise hypotension in humans. Exerc Sport Sci Rev. 2001;29:65-70. PMid:11337825. http://dx.doi. org/10.1097/00003677-200104000-00005

27. Chen CY, Bonham AC. Postexercise hypotension: central mechanisms. Exerc Sport Sci Rev. 2010;38:122-7.
PMid:20577060 PMCid:PMC2936915. http://dx.doi. org/10.1097/JES.0b013e3181e372b5

28. Santana HA, Moreira SR, Botelho WB N ${ }^{\circ}$, Silva CB, Sales MM, Oliveira VN, et al. The higher exercise intensity and the presence of allele I of ACE gene elicit a higher postexercise blood pressure reduction and nitric oxide release in elderly women: an experimental study. BMC Cardiovasc Disord. 2011;11:71. PMid:22136292 PMCid:C3261092. http://dx.doi.org/10.1186/1471-2261-11-71

29. Moreira SR, Arsa G, Oliveira HB, Lima LC, Campbell CS, Simões HG. Methods to identify the lactate and glucose thresholds during resistance exercise for individuals with type 2 diabetes. J Strength Cond Res. 2008;22:1108-15. PMid:18545200. http://dx.doi. org/10.1519/JSC.0b013e31816eb47c

30. Simões HG, Hiyane WC, Benford RE, Madrid B, Prada FA, Moreira SR, et al. Lactate threshold prediction by blood glucose and rating of perceived exertion in people with type 2 diabetes. Percept Mot Skills. 2010;111:365-78. PMid:21162440. http://dx.doi.org/10.2466/06.13.15.27. PMS.111.5.365-378

\section{Correspondence}

\section{Sérgio R. Moreira}

Universidade Federal do Vale do São Francisco (UNIVASF)

Av. José de Sá Maniçoba, s/n, Centro

CEP 56304-205, Petrolina, PE, Brasil

e-mail: sergio.moreira@univasf.edu.br 